\title{
Dentigerous cyst arising from a denticle in a primary teeth- a rare case report with brief review of literature
}

\author{
Jimsha Kumaran ${ }^{1}$ and Jonathan Mariappan ${ }^{1}$ \\ ${ }^{1}$ Mahatma Gandhi Postgraduate Institute of Dental Sciences
}

March 25, 2021

\begin{abstract}
Odontogenic cysts are derived from odontogenic epithelium which may develop before or after the formation of tooth. Most of these are developmental in origin. While dentigerous cysts are common odontogenic cysts that are related to the crown of the impacted tooth and known to arise from reduced enamel epithelium.

\section{DENTIGEROUS CYST ARISING FROM A DENTICLE IN A PRIMARY TEETH - A RARE CASE REPORT WITH BRIEF REVIEW OF LITERATURE}

\begin{abstract}
Odontogenic cysts are derived from odontogenic epithelium. Which may develop before or after the formation of tooth. Most of these are developmental in origin. While dentigerous cysts are common odontogenic cysts that are related to the crown of the impacted tooth and known to arise from reduced enamel epithelium.Dentigerous cyst is a type of developmental odontogenic cyst and has a rate between $20 \%-24 \%$ in allthe jaw cyst.Dentigerous cyst arising from primary dentition is very rare.A 5 year-old boy with swellingand pain in the jaw that were evaluated clinically,radiographicallyand histopathologically it was diagnosed as dentigerous cyst arising from a denticle.
\end{abstract}

Key words: Dentigerous cyst, Primary teeth, Denticle, Reduced enamel epithelium

\section{Introduction}

Kramer (1974) has defined cyst as a pathological cavity having fluid, semifluid or gaseous contents and which is not created by the accumulation of pus. Head and neck region is the more common site for the cystic lesion, this is because of the complex embryology and development of teeth with the presence of varying amount of residual islands which are more prone to entrapped and develop of a cystic lesions in future ${ }^{1,2}$. Dentigerous cyst is a type of developmental odontogenic cyst and has a rate between $20 \%-24 \%$ in all the jaw cyst, arising from fluid accumulation between the reduced enamel epithelium and erupting tooth resulting from the obstruction of veins during eruption and are radiographically seen to be attached to the neck of the teeth. This type of cyst always arises from the crown of an unerupted or impacted teeth, supernumerary ,or from an odontome. This cyst is frequently discovered when routine radiographs are taken to investigate a failure of tooth eruption, a missing tooth or mal alignment. Dentigerous cyst is seen mostly in a wide age range, most frequently reported in 10 to 30 years of age. The frequency of dentigerous cyst in children has been reported to be very low in literature ${ }^{3}$.

According to the literature review pediatric cystic lesions of the jaws are very rare and less cases have been reported from Asian population, around $20.2 \%$ dentigerous cysts particularly amongst Indians. The present case was unique in that of a dentigerous cyst which was arising from a denticle. 


\section{Case report}

A 5 year old boy reported to our department with pain and swelling in the left upper back teeth for past 1 month. Initially the swelling was small and gradually attained to the present size associated with fever .Facial asymmetry was evident due to the diffuse swelling in the left side of the face. On palpation swelling was firm to hard in consistency, tender and there was a slight local rise in temperature. On general examination, the patient was apparently healthy without any significant past medical history and routine hematological examination were within the normal limits.

A single left submandibular lymph node was enlarged measuring around $1.5 \times 2 \mathrm{~cm}$ in size, it was tender, mobile and firm in consistency. On intra oral examination there was an enlargement of the gingiva extending from the distal side of tooth 63 till the distal aspect of 65 obliterating the buccal vestibule, extending palatally $1 \mathrm{~cm}$ from the midline. The swelling was firm, tender and pus discharge through buccal gingiva in relation to 64 , pseudopocket was present, clinically teeth in the vicinity of the swelling appeared malformed and slightly yellowish brown with chipping of enamel on probing and displaced from the arch. With the above clinical findings a provisional diagnosis of dento alveolar abscess in relation 64 and 65 was given. Differential diagnosis of infected radicular cyst was also considered.Aspiration was not attempted due to pus discharge.IOPA radiograph was not taken as the patient had gagging and was not cooperative.Orthopantomograph revealed all the primary teeth to have erupted, permanent tooth germs in the developing stage, except 24,25 where the permanent tooth bud was absent. There was an ill-defined radiolucency in the left posterior maxilla extending from distal aspect of 63 till the distal aspect of 65 extending till the middle third of the root with complete loss of lamina dura in relation to 64 and 65 with ill-defined radiopacity at the interdental area of 64 and 65.(Fig.1)There was obliteration of the pulp chamber in relation to 64,65 with open apex. Follicular space was well appreciated in all the permanent developing tooth bud.

Enucleation of the lesion was done under general anesthesia along with extraction of 64 with tooth fragment showing several tooth like structures,(Fig.2) closure done with 3-0 vicryl suture, antibiotics were prescribed to prevent postsurgical infection.Microscopically the section showed soft tissue component consisting of thin odontogenic lining epithelium with a fibrous capsule, dense inflammatory cells were present,a normal tooth exhibiting dentinal tubule in an organic pattern.(Fig.3)The histopathology of the lesion was suggestive of a Dentigerous cyst probably associated with a denticle with secondary infection.

\section{Discussion}

Odontogenic cysts are defined as those cysts that emerge from odontogenic epithelium. Children have greater capacity to regenerate the bony structure compared to adults moreover teeth with open apices have greater eruptive potential. Literature concerning the cystic lesions of the jaw in a pediatric population is very rare.However, in the pediatric population, developmental dentigerous cysts predominate and tend to exist around impacted or unerupted teeth.In the present case a 5 year old boy was diagnosed with dentigerous cyst arising from a denticle. So far cases have only been reported as dentigerous cyst arising from impacted permanent teeth, primary and supernumerary and even from odontomes.

Radiographically an ill-defined radiolucency was evident, however the catchy point was a tooth like fragment which was present in between 6465 ,which was not a fractured segment of the tooth.

In the literature review many studies reported the incidence of occurrence of pediatric cystic lesions of the jaw bone .According to Telang et $\mathrm{al}^{3}$ in their 19-year retrospective study of cystic lesions of pediatric and adolescent population they found that around $43.2 \%$ of radicular cysts followed by $20.2 \%$ dentigerous cysts.In a study done by SK Padmakumar et $\mathrm{al}^{4}$ over a period of 12 years $(64.8 \%)$ were developmental in origin, $(33.6 \%)$ were inflammatory in origin and the rest of the cases included aneurysmal bone cysts, epidermoid cyst and nasopalatine cyst. Amongst the developmental cysts, dentigerous cysts (45.6\%) were found to be the most common followed by odontogenic keratocysts (5.6\%) and among the cysts of inflammatory origin, radicular cysts $(31.2 \%)$ were found to be the predominant type. The differences in prevalence of each type of jaw cyst during a lifetime may point toward a multifactorial polygenic pattern rather than a monogenic pattern. One of the reasons could be that during the pediatric age period the jaws are involved in intense 
developmental processes, growth of the maxillofacial skeleton and development of the primary and permanent dentition. Some of these are gene dependent. In the case of KCOT (odontogenickeratocysts or primordial cysts), it has been found that point mutation occurs in the suppressor gene PTCH mapped onto chromosome $9(\mathrm{q} 22.3-\mathrm{q} 31)^{5}$.

Management is mainly restoring function and esthetics and routine follow up is needed mainly in the pediatric age group. Any remnant can form a cystic lesion when the growth potential still persists. A one-stage surgical treatment and follow up was done after 6 months. The cystic lesion had completely healed and normal bone formation was evident.

\section{Conclusion}

This case report is unique in the association of a dentigerous cyst with a denticle, which by definition is a small tooth like structure bearing histological similarity to a tooth.Literature is voluminous with association of dentigerous cyst with odontomes, however to the best of our knowledge this is the first case wherein an association with a denticle has been established histologically.

\section{Key Clinical Message}

\section{WHY THIS PAPER IS IMPORTANT TO PEDIATRIC DENTIST}

- FIRST OF ITS KIND TO BE REPORTED IN THE LITERATURE

- IMPORTANCE OF PEDIATRIC ORAL RADIOLOGY

- DIAGNOSTIC SIGNIFICANCE OF HISTOPATHOLOGY

\section{Corresponding Author:}

Dr Jimsha V.K

Address: Department of Oral Medicine and Radiology, Mahatma Gandhi Postgraduate Institute of Dental Sciences Pondicherry, Puducherry (UT), India.

Phone numbers +91 9894089313

E-mail address: dr.jimsha.mds@gmail.com

\section{Authors}

1.Jimsha V.K ${ }^{1}$, M.D.S.

2. Jonathan Daniel $\mathrm{M}^{2}$, B.Sc, M.D.S.

1. Assistant Professor, Department of Oral Medicine and Radiology, Mahatma Gandhi Postgraduate Institute of Dental Sciences Pondicherry, Puducherry (U.T), India.

2.Associate Dean,Professor and Head, Department of Oral Medicine and Radiology, Mahatma Gandhi Postgraduate Institute of Dental Sciences Pondicherry, Puducherry (U.T), India.

\section{Conflict of Interest-NIL}

\section{REFERENCES}

1.Shear M, Speight P. Cysts of the oral and maxillofacial regions.4th ed. Oxford: Blackwell Munksgaard; 2007. Classification and frequency of cysts of the oral and maxillofacial tissues1-2.

2. Neville BW, Damm DD, Allen CM, Bouquot JE. Odontogenic cysts and tumors. Oral and maxillofacial pathology. 2nd ed. Philadelphia, PA: WB Saunders CO; 2002. p. 590-610. 
3.Telang A, Lahari K, Pushparaj S. Odontogenic cysts in children: A 19-year institutional review. Lat Am J OrthodPed Dent [cited 2011 June]. Available at: http://www.ortodoncia.

ws/publicaciones/2011/art13.asp.

4.SK Padmakumar, 2VT Beena, 3Devu Aloka, 4Rupali Lav, 5R Sivakumar A 12-Year Institutional Study Cysts of the Jaws in Pediatric Population:

Oral and Maxillofacial Pathology Journal, January-June 2015;6(1):532-536.

5.James R.H , Edward e III , Contemporary oral and maxillofacial surgery ( Mosby Elsivier :2008 .pp453-59.

\section{LEGENDS:}

1.figure 1.Ill-defined radiolucency in relation to 64 with widened pulp chamber in relation to 64,65 , all the primary teeth are erupted,permanent tooth germs in the developing stage except 24,25 are missing.

2.figure 2. Surgically excised specimen of multiple teeth like structures.

3.figure 3. Histopathology showing soft tissue component consisting of thin odontogenic lining epithelium with a fibrous capsule, and dense inflammatory cells.

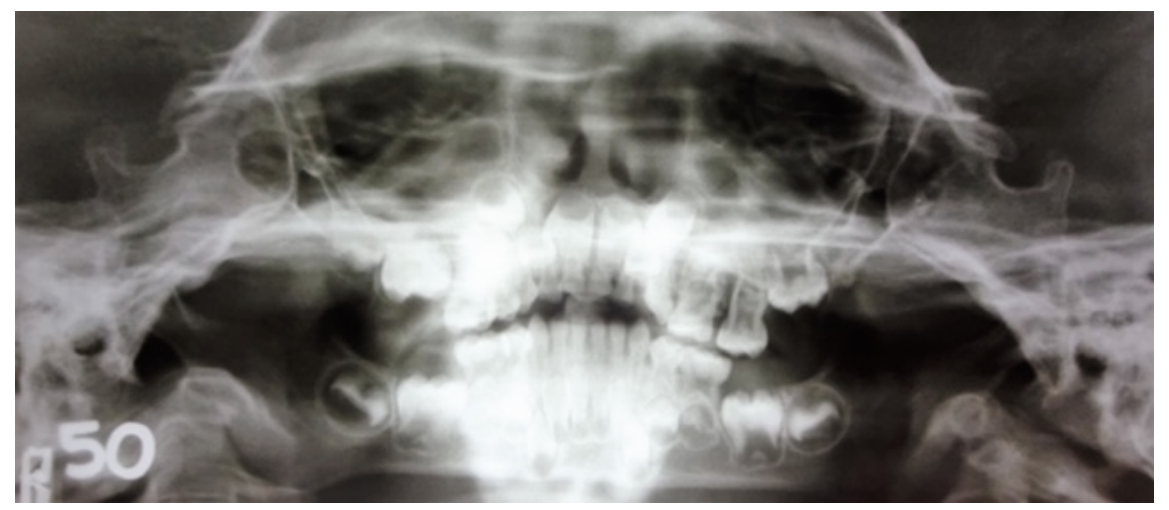




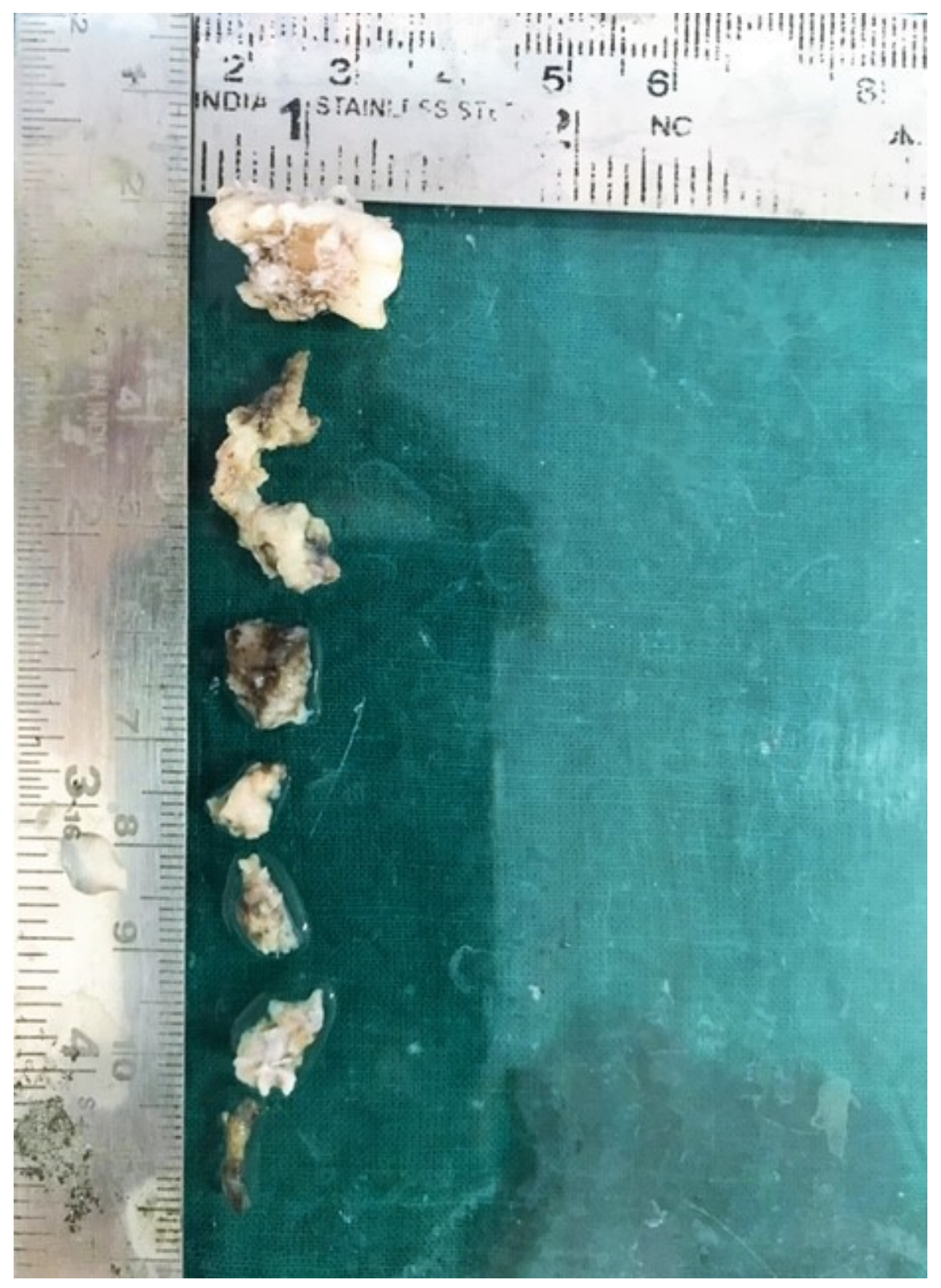




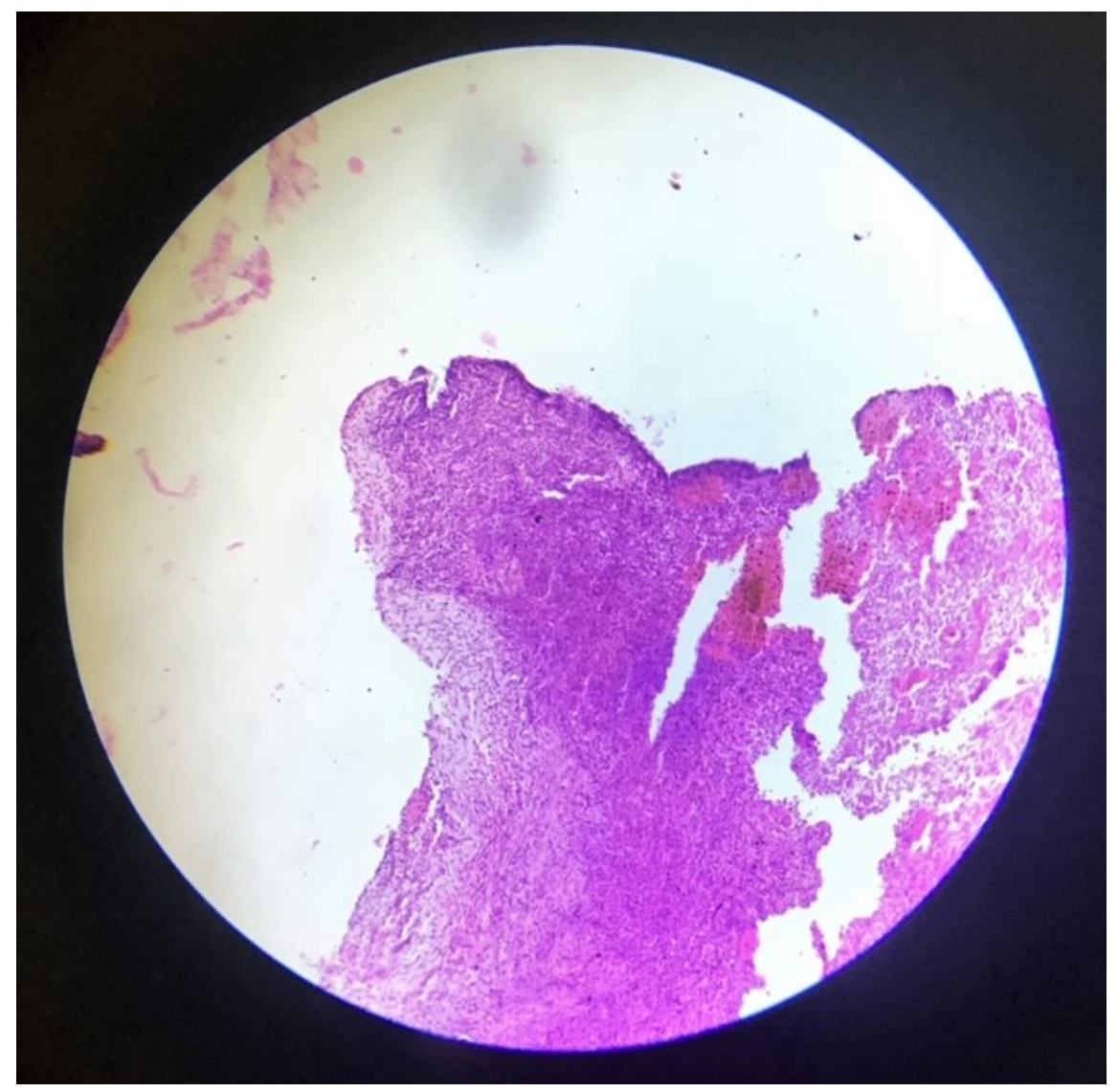

